\title{
Ergonomic aspects to be considered in planning public spaces destined for elderly people
}

\author{
Marcella Viana Portela de Oliveira Cunha ${ }^{\mathrm{a},}$ Angelina Dias Leão Costa ${ }^{\mathrm{b}}$ and Mariama da Costa Ireland ${ }^{\mathrm{c}}$ \\ ${ }^{a}$ Postgraduate Course in Architecture and Urbanism at the Federal University of Paraíba, UFPB. \\ ${ }^{\mathrm{b}}$ Department of Architecture and Urbanism at the Federal University of Paraiba, Postgraduate Course in \\ Architecture and Urbanism, Thermal Comfort Laboratory, João Pessoa - PB. \\ ${ }^{\mathrm{c}}$ Postgraduate Course in Architecture and Urbanism at the Federal University of Paraiba, UFPB.
}

\begin{abstract}
As has happened in many other countries, Brazil has also witnessed an evident change in the question of accessibility over the last twenty years. In line with this theme, that of old age has only become evident in the last two decades. For a long period of time, the elderly have been systematically ignored as an object of investigation and have not been contemplated with consistent public social policies. Therefore, the main objective of this research is to verify the conditions of physical accessibility that allow the elderly to use public spaces, taking as a study case the São Gonçalo square and the Solón de Lucena Park, in the city of João Pessoa - PB, identifying the biological and functional losses suffered by elderly people due to the aging process and verifying the specific physical needs of this segment of the population. Qualitative methods were adopted, such as systematic observations with the production of behaviour maps, in addition to a review of the literature and analysis of the data. The research identified problems related to the physical accessibility of the elderly to public spaces that generate difficulties for displacement, use, information and orientation, contributing to the planning and ergonomic guidelines which aim at improving these environments, such as the use of different and contrasting colours on the urban furniture and floor, for example.
\end{abstract}

Keywords: accessibility, the elderly, public spaces.

\section{Introduction}

Medical advances and the improvement in the general living conditions of the population, allied to rising levels of personal and environmental hygiene in residences as well as at work, have resulted in the raising of the average life expectancy of Brazilians (life expectancy at birth) from 45,5 years, in 1940, to 72,7 years, in 2008 , which represents an additional 27,2 years of life. According to the IBGE's projection [7], the country will continue to add years to the average life expectancy of its population, reaching in $2050,81,29$ years, basically the same present level of Iceland $(81,80)$, China $(82,20)$ and Japan $(82,60)$.

On the basis of this, the typically triangular form of the Brazilian population pyramid, with a wide base, is being replaced by the pyramid of a society in rapid " process of aging, that is characterised by the reduc-

*Corresponding authors. marcellaportela@hotmail.com tion of the relative participation of children and young people, followed by the increase of the proportional weight of adults and, particularly, of the elderly. In 2008, while children from 0 to 14 years old represented $26,47 \%$ of the total population, the contingent of 65 years old or more represented $6,53 \%$. In 2050 , the first group will represent $13,15 \%$, and the elderly population will pass $22,71 \%$ of the total population, according to IBGE [7].

In this sense, the city has to be prepared to receive this population, offering adequate spaces for conviviality adapted to their specific needs, since, with the passing of the time, these people present biological and functional losses, due to the aging process, that make some of their daily activities more difficult. In addition, there is a weakening of the group of relationships of people over 60 years old, as they no 
longer have their group of work colleagues and some members of the family and friends are lost.

Therewith, it is necessary for professionals in the area of architecture, engineering and design, to plan adequate spaces, environments and services for this parcel of the population, specially in relation to security, comfort and autonomy, focusing on decisions capable of minimizing the risk of falling that presents high incidence in this phase of life and improve the quality of life and social inclusion of the elderly population. We know that even though there is much research related to planning the environment for the elderly, these are generally directed at institutional homes and/or residential environments. Nevertheless, the problems related to physical-spatial accessibility are not restricted to internal environments. A large number of the elderly use public areas for leisure, particularly squares and parks relatively near to their residences. In spite of this, these areas, as a rule, were not planned taking into consideration the specific needs of this population. For this reason, understanding of the difficulties of access and use of the public and private spaces is fundamental for the planning of spaces that attend to their real needs.

In this sense, it is evident that the urban environment, due to its complexity, needs to be treated with a general view, in which accessibility is a basic aspect for the promotion of an adequate environment for the needs, capacities, abilities and limitations of its users.

Therefore the objective of this article is to raise important ergonomic aspects to be considered in the planning of public spaces destined to the elderly, using as case studies the São Gonçalo square and the Solon de Lucena Park, in the city of João Pessoa PB.

\subsection{The present context of the elderly}

The ageing of the population is a world wide phenomenon that began, originally, in developed countries due to the decrease in mortality, the great advances in medical knowledge, the improvement in nutrition, the elevation of levels of environmental and personal hygiene in residences as well as in the work environment, and to technological advances. In this context, the increase in the number of elderly people has provoked the need for adequate housing, leisure and transportation.

However, disinformation about the ageing of the population, the biological/functional losses due to this process, and consequently the real needs and specificities which this parcel of the population demands is still very high. The World Health Organization (WHO)[9] defines the elderly population as that over sixty years of age, but makes a distinction as to the place of residence as it is linked to the quality of life. "In developed countries people are considered elderly when they reach sixty-five years of age. In developing countries people are considered elderly when they reach sixty years of age [9]."

The Brazilian government considers elderly those persons who are sixty years of age, and for this article, we shall consider the elderly as people who are 60 years old or more and who present consequences of the ageing process that make daily activities difficult.

\subsection{Alterations resulting from the ageing process}

Biologically, the ageing process is a natural, dynamic, progressive and irreversible process, that is installed in each and every individual at birth and which accompanies him throughout his life, ending with his death. In this trajectory, it provokes many morphologic modifications in his organism, alterations in the shape of the body, (the appearance of wrinkles, white hair and others); physiological modifications, related to the organic functions (the diminishing functions of the liver, among other organs, for example); and biochemical modifications, directly linked to transformation of chemical reactions present in the organism (changing glandular activity, among others). In the following section functional alterations which influence directly the use of public space will be treated.

In relation to the muscular-skeletal system, there is a loss of 10 to $20 \%$ in muscular strength, higher levels of fatigue, reduction in the regenerating capacity and in the ability to maintain static force. In addition to these, there are other losses such as: reduction in agility, coordination, equilibrium, flexibility, articular mobility and increase of rigidity of the cartilage, of the tendons and the ligaments. All of these modifications damage the functioning of the loco motor system and the equilibrium of the elderly, causing changes in posture and mobility [11], making walking slower and more tiresome.

Regarding cognitive alterations, the auditory dysfunction is emphasised, with the reduction of hearing, and physiological changes in the visual process. To perform a task with the same precision, the visual necessity of the quantity of light could be doubled at the age of sixty in comparison with the age of twenty. 
The elderly population is also more sensitive to levels of bright light than the younger population [5].

Amongst the visual alterations that the elderly suffer, are: (1) visual accommodation, which is the capacity that the human eye has to adjust to changes of distance between objects; (2) visual adaptation, which is the sudden change of light intensity; (3) visual fatigue, which demands greater effort to focus on small details; (4) light blindness, which is produced by the presence of excessively bright lights or areas; (5) visual acuity, which is the visual capacity to discriminate small details; (6) capacity of colour perception, witch is a characteristic of the visual sensation caused by different wave lengths.

All of these alterations compromise the capacity of the elderly population to perform their daily life activities, as well as their mobility and social wellbeing. On the basis of this, it is necessary to plan objects, furniture, equipment and urban spaces with a clear and intuitive language, so that the elderly can identify every element more easily.

\subsection{Accessibility for the elderly}

Physical accessibility is defined by the NBR 9050 norm [1] as the possibility and the condition of access, perception and understanding for the use of buildings, space, furniture, urban equipment and elements with safety and autonomy. Therefore, in order for spaces to be accessible, it is necessary to consider four components identified by Dischinger and Bins Ely [3], which are: the orientation/information that aims to facilitate the comprehension of spaces and its information, for informative necessities; displacement that is the condition of movement in horizontal and vertical paths and their continuity; the use, which foresees access and utilization of spaces and their equipment, for physical needs; and communication which seeks to provide user interaction, for social needs.

Another important concept is that of Universal Design, as it establishes that the planning of products, buildings and open spaces, should allow everyone to use them, with or without physical or cognitive deficiencies [8], and proposes seven basic principles: (1) equitable use, (2) flexibility in use, (3) simplicity and intuitivism, (4) easy and efficient perception of information, (5) mistake tolerance, (6) reduction of physical effort, and (7) adequate spaces and dimensions for approximation and use.

The importance of accessibility and universal design has increased with the growth in the number of people with physical or cognitive deficiencies, with the demographic aspect, including developing countries, which has increased the life expectancy of the population, implying a greater presence of the elderly.

Therefore, it is relevant to adjust urban spaces, eliminating physical barriers (architectonic) that might make access difficult or even impeding safe access for the elderly. Squares and parks are spaces that make free and unlimited access possible to any social group, offer contact with nature to the target public, facilitate interaction with other people, promote physical well-being, allow the practice of outdoor sports as well as contact with the sun [4].

\section{Methodology}

The structure of this article considers the following steps:

\subsection{Theoretical foundation}

Research in articles (norms, laws and decrees) which deal with accessibility in the built environment and the biological/functional losses which people suffer with the ageing process and that generate difficulties in the use of public space, squares in particular.

\subsection{Field research}

In this phase it was possible to know the places of the research in more detail, to perceive how the elderly use urban space and which are the main physical barriers and facilitators that this group has found in the use of public space. In order to obtain all the desired information, qualitative methods were adopted, which are described as follows:

\subsubsection{Systematic observations}

To accomplish systematic observations, the techniques of photographic recording, architectonic survey and behaviour maps were applied.

a) Characterization and analysis of the physical space.

This consisted of registering the built space with regard to the conditions of accessibility and the physical characterization of the site and its immediate surroundings, on the basis of exploratory visits, where data surveys were carried out, based on photographic recording, direct observation, notes and sketches.

For a better diagnosis, the following aspects were observed: localization, presence or absence of the 
elderly, safety, composition of the surroundings, existing access and urban elements, such as furniture, covering material, lighting and the existence of vegetation, in addition to identifying specific spaces which each space contains, describing them spatially and registering the activities and the behaviours of the target public in the development of the activities.

b) Behaviour maps

Behaviour maps are physical records of the activities performed in a repetitive and systematic manner by unit of space, during pre-determined periods of time observing the age range of those individuals or groups that are performing these activities [2].

In this specific case, the maps were elaborated on one weekday and one day at the weekend, at two different times - the beginning of the morning and the end of the afternoon, times when urban spaces are most used by the elderly, identifying activities and behavioural patterns which are repeated in time and space, by means of notes on floor plans, that generated a synthetic behaviour map.

\subsubsection{Questionnaires}

A questionnaire can be defined as an instrument of research that contains an ordered series of questions related to a determined topic or problem [10], with the aim of obtaining information about behaviours, attributes and attitudes of the users of built environment.

With regard to its content, the questionnaire was elaborated with closed, open and dichotomised questions related to the perception of the user and divided into three parts: the first one characterized the users taking into consideration their age range, educational level, sex, neighbourhood where they live and if they have any form of deficiency or limitation due to the ageing process. In the second part we observed how elderly people use the urban space, raising questions such as frequency and the times of permanence, use and activities and security in accessing the spaces. The last part was destined to identify problems in the urban spaces and suggestions for improvement.

\subsection{Analysis and systematization of data}

In this phase, the data was analysed, systematized and generated planning and ergonomic guidelines for the improvement of the quality of the urban public spaces studied which would benefit the user population and could provide feedback for the planning process on other opportunities.

\section{The urban spaces studied}

\subsection{São Gonçalo Square}

São Gonçalo square is located in the Torre district of João Pessoa - PB, where the elderly population is accounts for $15,08 \%$ [6] of the total population and possesses an area of $5622,60 \mathrm{~m} 2$. In this square a significant presence of the elderly population was verified developing activities such as: walking, stretching, games, contemplation, among others, in addition to offering urban equipment that allow the use and development of activities typical of the elderly public.

The buildings in its immediate surroundings are mostly residential, commercial and service oriented. The existing urban furniture - benches, garbage bins and tables for games - are in good state of conservation, as is the floor made of smooth concrete. The lighting is provided by the randomly ordered lampposts and the predominant vegetation is composed of big and medium sized trees and vegetation in the flowerbeds.

With regard to the specific spaces in the square, we identified: the leisure area, the games area, the circulation for pedestrians, the multi-sport court, the children's park, and the garden areas, as shown in figure 1 .

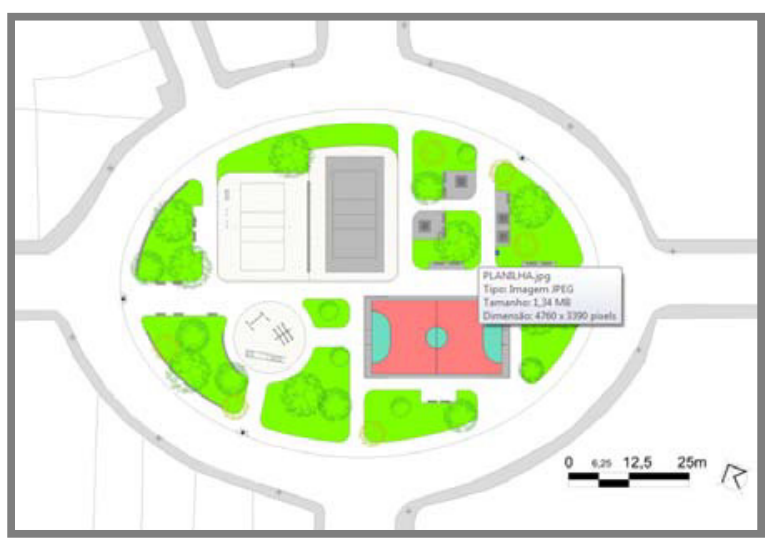

Figure 1. Map of the São Gonçalo square showing specific spaces.

The application of the behaviour map revealed the importance for the elderly people of spaces that make safe access possible and equipment adapted to their specific needs. An example of this is the lack of equipment for the practice of stretching and exercise by the specific age group, which obliges the elderly to use the urban furniture and existent vegetation to perform these activities. 
On the basis of the observations carried out for the production of behaviour maps, the São Gonçalo Square revealed itself to be a place where there is strong interaction between the elderly, encouraging new cycles of friendships, specially within the group formed to practice exercise, proportioning communication between the different generations, as showed in figure 2 .

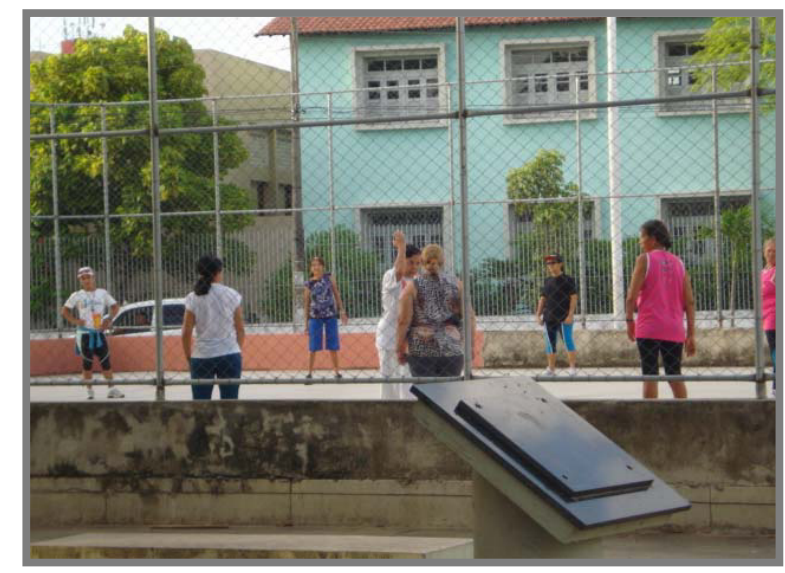

Figure 2. Photo showing a group of people practicing gymnastics, including the elderly.

In a general way, it was observed that the use of the square is greater in the southeast portion, both due to the existence of trees, with closed crowns, allowing prolonged permanence at the site, and due to the path giving access to the church that, on Sundays, attracts many faithful.

Thus, the production of the behaviour maps helped to know in detail the activities carried out by the target public and the localization of these people in the square's environment, identifying the most used paths and registering the behaviour and attitudes, indispensable information for achieving the objective of this research.

\section{Solon de Lucena Park}

According to the IBGE [6], the Centre district, where the Solon de Lucena Park is spatially located, has the largest index of elderly people in the capital, with $19,67 \%$ of its population formed by people who are 60 years old, totalling 893 people.

This area is characterised by its central location, surrounded by buildings with a wide number of different uses (residential, institutional, commercial and services) and, as being one of the main corridors of vehicular circulation in the city.

With regard to access, there are no pedestrian crossings for those on foot to cross roads in safety, although some lowered kerb stones were observed at some points. Access to the private transportation system is in evidence, with parking areas and taxi stands; and the public transportation, with a large number of bus stops near the location, which increases the flux of people and vehicles. Vegetation is highly visual due to the imperial palm trees around the park.

The presence of the elderly practicing leisure activities was verified during the application of the method. The activities preliminarily identified are of a physical nature, such as walking and stretching; and social nature, such as talking and contemplating the landscape, as in figure 4. The area is divided in four specific spaces: the sitting area, circulation area, fountains/ water sheets and garden areas, as showed in figure 3 .

Through the application of the behaviour maps it was possible to verify the inexistence in the park of the equipment necessary for the practical activities it houses like, for example, stretching, either in groups or individually.

As the park has few specific spaces and equipments, and presents a great flux of vehicles and buses, there are not many leisure options left, forcing and limiting the elderly to practice the desired exercise or activity, remaining for short periods of time in the park. 
Figura 3. Mapa do Parque Solon de Lucena.

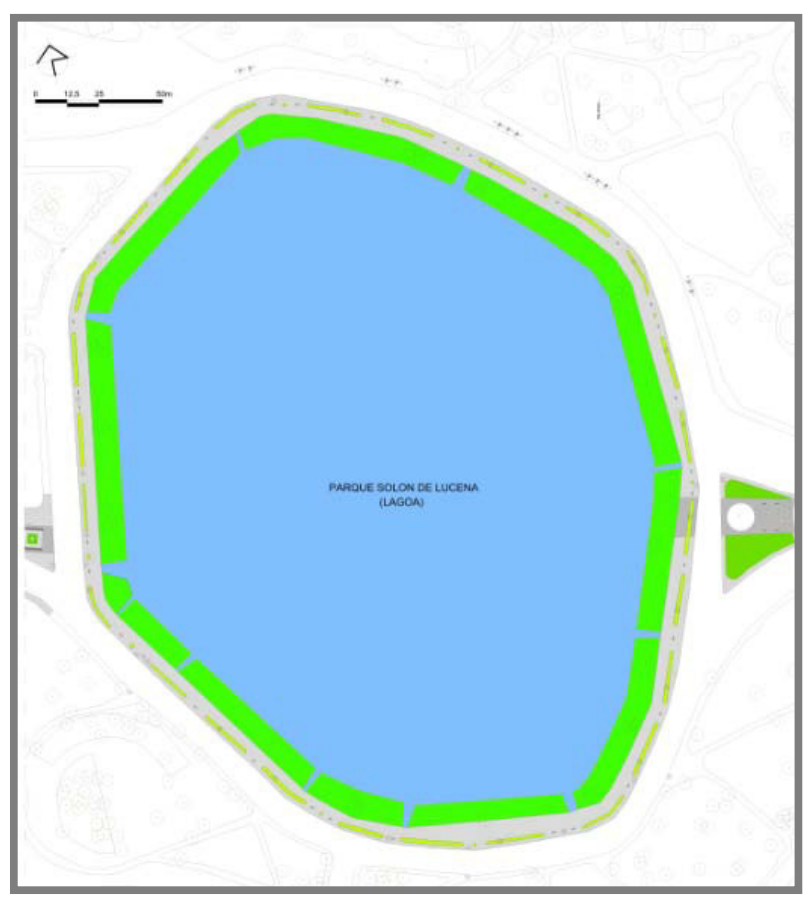

Figure 4. Picture showing elderly ladies walking

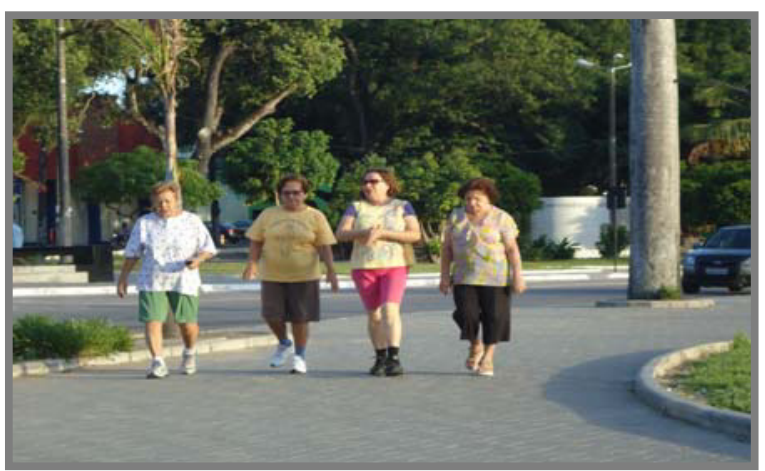

The most relevant problems were the lack of maintenance in cleaning the pedestrian circulation area, accumulating quantities of sand that make the floor slippery and difficult for walking. Another factor detected was the bad smell in certain areas of the park, due to clandestine sewage pipes that use the lake for their discharge. A majority of the urban furniture such as benches, garbage bins and raised signs, is in a good state of conservation, although the landscaping is not adequately maintained which leaves the flower beds in a poor state.
The data obtained were very useful to identify the activities and how they are spatially arranged, observing the movements and the distribution of the people in the considered environment.

\section{Results}

This research had as an objective to propose planning and ergonomic guidelines for free public urban spaces that will turn these locations into accessible spaces for the elderly population, identifying biological and functional losses that this population suffers due to the aging process, as to verify the special physical needs and limitations of this parcel of the population, besides studying the environment of the squares and parks verifying the activities practiced by the elderly people and how they use these environments.

For the results to be possible, we relied on the development of the theoretical foundation and filed research. The theoretical foundation contributed, among other factors, with the knowledge about the elderly people and the aging process. The modifications due to the aging process were understood and the consequent spatial needs of the targeted public were identified.

As to the fieldwork research procedures, the methodology used focused on identifying the difficulties faced by the elderly population to carry out activities. For this, the use of methodologies that complement each other in a logical and strategic way were necessary to achieve the objectives.

Based on the data obtained, the research identified some problems related to the four components of accessibility: information/orientation, displacement, use and communication. As to the orientation of public urban spaces we recommend the use of the same colour for the floor in the sitting area, to facilitate the identification of its use, as well as the use of different colours for the urban furniture, preferably contrasting colours with respect to the floor. With regard to the information signs, these must contain graphic images, pictograms and texts in contrasting colours for information and background, avoiding their location next to the ground and as frequently as possible to install digital terminals.

In relation to the safe displacement of the elderly in the urban space, we suggest that the sitting area must have visible access, as well as benches placed in a frontal position and with a minimal distance of ninety centimetres to allow an elderly person using a 
wheelchair to be able to move and interact with other users.

Long paths must be avoided, as they involve great physical effort, as well as the use of coverings that wear out with time and may create holes or unevenness on the floors. In addition, access with sinuous circulation and with sudden changes of direction should be avoided. There is a need for ramps.

Planning that contemplates areas with different leisure possibilities, flat plots, presence of urban furniture such as garbage bins and drinking fountains, correctly located and identified, as well as variation in the positioning of the benches, stimulating the interaction and communication among users, guarantee the safe use of public spaces. Besides this, lighting must be intermediate and low. The sitting area must be partly shaded and partly in the sun, offering a choice to its users.

In relation to the guarantee of good communication between the elderly, it is recommended that the benches should be placed in various ways stimulating the interaction and the communication between people.

Based on the methodology employed and the knowledge acquired from the bibliography consulted, it was possible to identify some of the problems that the elderly face with regard to information, communication, use and displacement in urban spaces. Therefore, the objective of the research is to provide planning and ergonomic guidelines for these environments, contributing with professionals interested in planning accessible squares and parks for this public, considering that frequently the lack of knowledge on the needs of the users produces projects with problems of accessibility.

\section{References}

[1] ABNT - Associação Brasileira de Normas Tecnicas. NBR 9050: Acessibilidade de Pessoas Portadoras de Deficiências a Edificações, Espaço, Mobiliário e Equipamento Urbano. Rio de Janeiro: ABNT, 2004

[2] Bechtel, Robert B.; Marans, Robert W.; Michelson, William. Methods in environmental and behavioral research. New York: Van Nostrand Reinhold, 1987.

[3] Dischinger, Marta; Bins Ely, Vera H. M. Promovendo acessibilidade nos edifícios públicos: guia de avaliação e implementação de normas técnicas. Santa Catarina: Ministério Público do Estado, 2006.

[4] Dorneles, Vanessa Goulart. Acessibilidade para idosos em áreas livres públicas de lazer. Florianópolis, 2006. 178p. Dissertação (Mestrado em Arquitetura e Urbanismo) Programa de Pós - graduação, UFSC, 2006.

[5] Freire, Sheila Azevedo, et al. Avaliação lumínica em instituições asilares para idosos. In: Anais do XIII Encontro Nacional de Tecnologia do Ambiente Construído. Canela, 2010.

[6] IBGE, Instituto Brasileiro de Geografia e Estatística. Censo Demográfico e Contagem populacional. Disponível em <http://www.sidra.ibge.gov.br/bda/tabela/protabl. . 2007. Acesso em 04/11/2010.

[7] IBGE, Instituto Brasileiro de Geografia e Estatística. População brasileira envelhece em ritmo acelerado. Disponível em <http://www.ibge.gov.br/home/presidencia/noticias> 2008 . Acesso em 14/11/2010

[8] Mace, R.; Hardie, G.; Place, J. Accessible Environments: Towards Universal Design. In: Preiser, w., Vischer, J., White, E. Design intervention: toward a more humane architecture. New York: Van Nostrand Reinhold, 1991. 374p.

[9] OMS - Organização Mundial de Saúde (Who - World Health Organization). Active ageing: a policy framework. Um projeto de politica de saude. Madri: Segundo Encontro Mundial sobre Envelhecimento, 2002.

[10] Rheingant, et al. Observando a qualidade do lugar: procedimentos para a avaliação pós-ocupação. Rio de Janeiro: Universidade Federal do Rio de Janeiro, Faculdade de Arquitetura e Urbanismo, Pós-Graduação em Arquitetura, 2009.

[11] Santos, Silvana Sidney Costa. Enfermagem gerontogeriátrica reflexão a ação cuidativa. São Paulo. , 2 Ed. Robe Editorial., 2001 . 